\title{
Building Salmon Resilience: Lessons Learned from The Great East Japan Earthquake (GEJE) and Other Ecological Disasters
}

\author{
James R. Irvine ${ }^{1}$, Masahide Kaeriyama ${ }^{2}$, Shigehiko Urawa ${ }^{3}$, and Jun Aoyama ${ }^{4}$ \\ ${ }^{\text {I}}$ Pacific Biological Station, Fisheries and Oceans Canada, Nanaimo, BC, Canada \\ ${ }^{2}$ Arctic Research Center, Hokkaido University, Sapporo, 001-0021 Japan \\ ${ }^{3}$ Fisheries Resources Institute, Japan Fisheries Research and Education Agency, Sapporo 062-0922, Japan \\ ${ }^{4}$ Atmosphere and Ocean Research Institute, University of Tokyo, Otsuchi, 028-1102 Japan
}

Keywords: GEJE, salmon, tsunami, resilience, disaster management, hazard mitigation, genetic diversity

Introduction

Ecological disasters that occur throughout the world can be natural (e.g., earthquakes, tsunamis), anthropogenic (a consequence of human activity e.g., dam breaching, pollution), or sometimes a hybrid (e.g., some landslides). Disaster risk management plans lay out the goals and means to reduce disaster risks, often guided by the Sendai Framework (United Nations Office for Disaster Reduction 2015). Among other things, this Framework identified that national governments have the primary responsibility of reducing disaster risk, but that responsibility should be shared with local governments, the private sector, and other stakeholders.

Ecological disaster literature often focuses on resiliency, first defined by Holling (1973) as "a measure of the persistence of systems and of their ability to absorb change and disturbance and still maintain the same relationships between populations or state variables." Climate change and major anthropogenic modifications to salmon ecosystems can compromise the resilience of salmon populations to major disturbances (Waples et al. 2009). The importance of maintaining habitat, ecosystem and genetic heterogeneity to maintain resiliency and hence, conserve salmon populations, is well-documented (e.g., Bottom et al. 2009). Identifying who is responsible for the mitigation of harmful effects of ecological disasters on salmon and how this is best achieved is vitally important.

It has been ten years since the Great East Japan Earthquake (GEJE) and tsunami of 11 March 2011 resulted in horrendous damage to local marine ecosystems of northeast Honshu, Japan. This region of Japan is not unique in experiencing earthquake generated tsunamis that cause catastrophic damage. In the six years preceding the GEJE, the 2005 Sumatra, 2006 Java, 2009 Samoa, 2010 Chile and 2010 Mentawai tsunamis each caused significant damage (Kontar et al. 2014). Not surprisingly, the overriding response to protect human lives often results in inadequate consideration of the environment, although increasingly balanced approaches to protect and restore coastal ecosystems are becoming more common (Santiago-Fandiño et al. 2014).

The decade long multi-disciplinary GEJE Tohoku Ecosystem-Associated Marine Science (TEAMS) project, established soon after the GEJE, was completed earlier in 2021. TEAMS sponsored numerous scientific events, created a website (http://www.jamstec.go.jp/i-teams/e/index.html) and database, and supported the publication of $>$ 120 documents, including findings relevant to salmon, some of which are described in other papers in this session.

We suggest that application of lessons learned from Japan's response to the GEJE, augmented by knowledge gained elsewhere, can mitigate future large-scale ecological disturbance effects on this and other coastal ecosystems supporting salmon. Our objective is to describe strategies (lessons learned) that can be used to build resilience within coastal salmonid ecosystems in order to facilitate recovery from ecological disasters, especially those pertaining to tsunami effects on the coastal ecosystem and anadromous salmon. We define resilience as the ability of the aquatic ecosystem to recover from major environmental disturbances.

\section{Building Resilience}

Many ecological disasters are foreseeable, although rarely does one know when such an event will happen. Japan, because it lies across several tectonic plates, is earthquake prone. The GEJE was the largest disaster in this region, but not the first, nor the last. The maximum height for the 2011 tsunami was $40.1 \mathrm{~m}$; earlier major earthquake generated tsunamis occurred in $1611(20 \mathrm{~m}), 1896(38.2 \mathrm{~m}), 1933(28.7 \mathrm{~m})$, and $1960(28.7 \mathrm{~m})$. Building resilience is extremely challenging when the timing and scale of the next event are unknown.

Major hazard planning processes have a Planning phase intended to precede a major ecological event that is followed by Immediate Response, Longer Term Recovery and Mitigation phases (Fig. 1). These steps are iterative and repeating because natural disasters repeat themselves. 


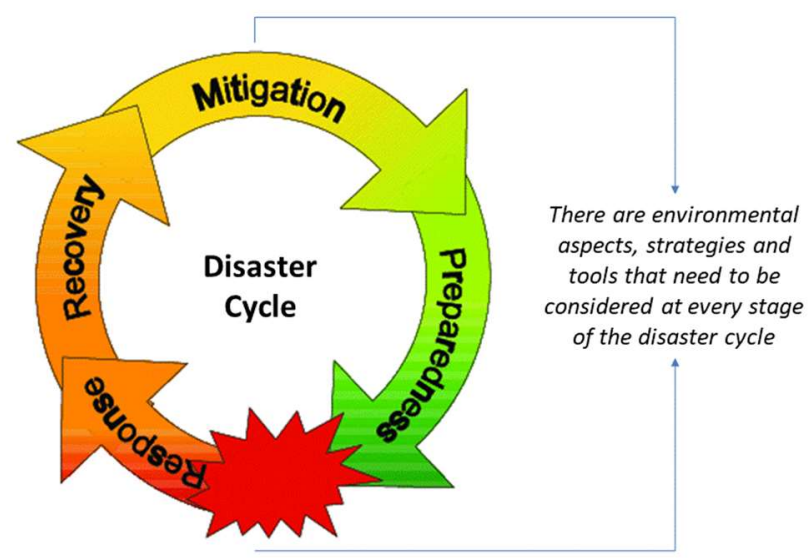

Fig. 1. The disaster management cycle (source: Srinivas 2020).

We describe these phases to build resilience within coastal salmonid and other ecosystems subjected to major ecological disturbances such as an earthquake-generated tsunami:

1. Planning (Build Resilience)

During the Planning phase, a hazard mitigation plan is developed with the primary goal of minimizing disaster impacts (e.g., https://www.fema.gov/sites/default/files/2020-06/fema-mitigation-ideas_02-13-2013.pdf; p. 55). The plan should identify risks and vulnerabilities in the region of focus (e.g., the Sanriku region of Northeast Honshu). After identifying these risks, long-term strategies are developed to protect people, natural resources (e.g., salmon), and property from similar events:

a. Map ecologically sensitive areas vulnerable to future inundation

b. Manage salmon facilities (e.g., net pens, hatcheries) within the inundation zone

i. Encourage tsunami resistant designs for existing facilities

ii. Limit new developments within the flood zone and consider relocating existing facilities above the maximum historical inundation level

c. Improve public and stakeholder awareness

d. Identify and understand inter-sectoral roles and responsibilities that will include broad participation (local government, public, stakeholders, and knowledgeable experts)

e. Identify effective communication approaches including how to get information to decision-makers quickly immediately following a disaster

f. Identify actions to be carried out during the recovery and mitigation phases, which are intended to reduce environmental and economic losses. These might include:

i. rebuilding or constructing appropriate physical structures (levees, dikes) with large setbacks,

ii. rebuilding or constructing suitable enhancement facilities outside the potential impact zone, and

iii. developing realistic plans to restore and maintain habitat and ecosystem diversity and connectivity, necessary for the replenishment and maintenance of genetic and phenotypic diversity. With respect to the GEJE, this would likely include creating and maintaining suitable habitat for natural salmon spawning upstream of the 2011 tsunami impact zone and ensuring these areas are adequately seeded by mature salmon in future years.

2. Immediate post-disaster response

Because of the often enormous scale of damage caused by major ecological disasters, the immediate response understandably focuses on human health and safety. Regardless of the specific focus of the response, it is necessary to:

a. Establish effective communication

b. Inventory the spatial scale and scope of the damage

c. Develop initial recovery goals with a timeline

3. Longer-term recovery and mitigation

Depending on the magnitude of the event, this can take many years. During this period, it will be necessary to:

a. Maintain effective communication among participants

b. Reach consensus on roles and responsibilities

c. Carry out a thorough assessment of damage and update recovery goals and timelines 
d. Review and update as necessary strategies identified in the hazard mitigation plan

e. Decide on action steps, secure funding, and implement activities for the restoration and adaptive management of habitat, ecosystems and facilities undertaken, many of which should have been identified during the preparedness phase.

\section{The GEJE Case Study}

TEAMS had a broad mandate that included, "restoration of fishery grounds and marine resources necessary through reconstruction of seedling production systems for salmon and trout..." (http://www.jamstec.go.jp/iteams/e/index.html). A multi-disciplinary team was established soon after the GEJE that included $\sim 200$ marine researchers. Work on several project areas was initiated (ecological succession in coastal fisheries, factors controlling coastal and open ocean ecosystem processes, data sharing, publication, and outreach) and five task groups were established. TEAMS sponsored numerous scientific events (including this third NPAFC-IYS workshop), created a website and database, and supported the publication of $>120$ publications as well as many posters and presentations.

As a result of TEAMS, relationships among government agencies and academic institutions, and regulations and policies pertaining to disaster management were strengthened.

Recovery and mitigation phase activities included: (1) construction of a $400 \mathrm{~km}$ seawall, (2) development of coastal dikes, (3) reconstruction of destroyed salmon hatcheries, and (4) tidal gates. However, the ecological effects of some approaches designed to protect people remain uncertain.

Long-term effects of the GEJE are still being revealed but early indications are that the marine ecosystem is being re-established, some local fisheries are rebuilding, and more natural chum salmon spawning than expected is occurring. Nevertheless, the rebuilding of local chum salmon populations is proving difficult. Recent survivals of chum salmon in other areas of Japan have also been poor; research is needed to disentangle the effects of GEJE from those affecting all Japanese chum salmon.

TEAMS researchers worked hard to better understand ecological effects from the GEJE. Time will tell whether the resiliency of the salmon and other aquatic resources have been restored. We encourage government agencies, academic researchers, and others to focus on updating and revising their hazard mitigation plans before the next inevitable disaster hits. To build resilience, plans should include restoring and maintaining habitat and ecosystem diversity and connectivity, necessary for the replenishment and maintenance of genetic and phenotypic diversity.

\section{Summary}

Lessons learned from Japan's response to the GEJE were augmented by relevant knowledge gained elsewhere. We described strategies to facilitate ecosystem recovery resulting from ecological disasters, especially those pertaining to tsunami effects on the coastal ecosystem and anadromous salmon. To prepare for natural disasters that tend to repeat themselves, a disaster management cycle that includes hazard mitigation plans should include: (1) a good understanding of inter-sectoral roles and responsibilities, (2) broad participation (public, stakeholders, and knowledgeable experts), (3) effective communication approaches, (4) appropriate physical structures (levees, dikes) with large setbacks, (5) suitable enhancement facilities outside the potential impact zone, and (6) realistic plans for restoring and maintaining habitat and ecosystem diversity and connectivity, necessary for the replenishment and maintenance of genetic and phenotypic diversity. After a disaster, there should be an immediate post-disaster response phase where the spatial extent of damage is determined as well as recovery goals with a timeline.

Strategies identified in the preparedness phase need to be updated as necessary and implemented during longer-term recovery and mitigation phases before the cycle repeats itself with the preparation of the next hazard mitigation plan.

\section{REFERENCES}

Bottom, D.L., K.K. Jones, C.A. Simenstad, and C.L. Smith (Editors). 2009. Pathways to resilient salmon ecosystems. Ecol. Soc. 14(1): 5. (Available at https://www.ecologyandsociety.org/issues/view.php?sf=34)

Holling, C.S. 1973. Resilience and stability of ecological systems. Annu. Rev. Ecol. Syst. 4: 1-23. doi: 10.1146/annurev.es.04.110173.000245.

Kontar, Y.A, V. Santiago-Fandiño, and T. Takahashi (Editors). 2014. Tsunami events and lessons learned. Advances in natural and technological hazards research, Vol 35. Springer, Dordrecht. 467 pp. (Available at https://link.springer.com/book/10.1007/978-94-007-7269-4) 
Santiago-Fandiño V. 2014. The tsunami and earthquake in Miyagi Prefecture and Sanriku 2011-2012: an overview. In Tsunami events and lessons learned. Advances in natural and technological hazards research. Edited by Y.A. Kontar, V. Santiago-Fandiño, and T. Takahashi. Vol 35. Springer, Dordrecht. pp. 1-54.

Srinivas, H. 2020. Pre- and post-disaster management: environmental management tools to reduce disaster risks. GDRC Research Output-Management Tools Series E-118. Global Development Research Center, Kobe. (Available at http://www.gdrc.org/uem/disasters/disenvi/tools/pre-post.html)

United Nations Office for Disaster Reduction. 2015. Sendai framework for disaster risk reduction 2015-2030. United Nations Headquarters, 32 pp. (Available at https://www.undrr.org/publication/sendai-frameworkdisaster-risk-reduction-2015-2030)

Waples, R.S., T. Beechie, and G.R. Pess. 2009. Evolutionary history, habitat disturbance regimes, and anthropogenic changes: What do these mean for resilience of Pacific salmon populations? Ecol. Soc. 14(1): 3. (Available at http://www.ecologyandsociety.org/vol14/iss1/art3/) 